\title{
Inlet Parameters Effects of Invelox on the Aerodynamic Performance using Numerical Simulation
}

\author{
A. Farokhzade ${ }^{\dagger}$ and M. J. Maghrebi \\ Faculty of Engineering, Ferdowsi University of Mashhad, Mashhad, Iran \\ †Corresponding Author Email: ali.farokhzade@mail.um.ac.ir
}

(Received January 8, 2021; accepted April 15 2021)

\begin{abstract}
Invelox is a structure that increases the wind velocity by collecting air from the higher level of ground. Previous studies showed that Invelox has the potential to capture air and increases the speed of wind, which means more power output. Although it was claimed that Invelox can capture air from all directions, its performance greatly depends on the angle of wind. In this study, the performance of Invelox is analyzed and improved for different wind directions by changing the number of blades. The results showed, however, the aerodynamic performance of all proposed Inveloxes has decreased due to increasing the wind angle, the five-blade Invelox outperforms the original model in output power by about $7 \%-20 \%$ in various wind directions. Furthermore, in order to reduce air escaping from the opposite side of Invelox, the length of the upper funnel has been increased. Results showed about $12 \%$ improving performance when the length of the upper funnel is equal to its diameter. The three dimensional models were analyzed by Ansys-Fluent, under steady-state conditions.
\end{abstract}

Keywords: Invelox; Ducted wind turbine; Speed ratio; CFD; Efficiency improvement.

\section{NOMENCLATURE}

$\begin{array}{ll}D & \text { upper diameter of funnel } \\ L & \text { length of upper funnel } \\ \text { pi } & \text { pressure } \\ \mathrm{Pi} & \text { average pressure } \\ \text { pi } & \text { fluctuating pressure } \\ \text { sij } & \text { strain-rate tensor } \\ \text { Sij } & \text { mean strain-rate tensor } \\ \text { SRavg } & \text { average speed ratio } \\ \text { SRmax } & \text { maximum speed ratio }\end{array}$

$\begin{array}{ll}\text { ui } & \text { wind velocity } \\ \text { Ui } & \text { average velocity } \\ \text { úi } & \text { fluctuating velocity } \\ \text { xi } & \text { direction } \\ i & \text { space index } \\ j & \text { space index } \\ \tau \text { ij } & \text { Reynolds stress tensor } \\ \rho & \text { density } \\ \mu & \text { viscosity }\end{array}$

\section{INTRODUCTION}

Wind energy has been used for many years in moving boats, cooling houses, running machinery and etc. Recently, the wind was used for producing electricity by utilizing wind turbines. Despite efforts that have been made to increase the efficiency of wind turbines, the cost of starting a fossil fuel power plant is lower than a wind power plant (Bonass and Rudd 2010).

If a wind system can provide high efficiency at low cost, it will undoubtedly be a substitute for conventional fuel systems. Numerous types of wind turbines such as horizontal and vertical wind turbines have been presented (Burton et al. 2001). Furthermore, several review papers were published to investigate the aerodynamic performance of wind turbines (Walker 2011; Kyozuka 2008; Grant et al. 2008; Eriksson et al. 2008).

Not only does the aerodynamic performance of a wind turbine make a wind project economically reasonable, but also the wind speed at the site of the project is an essential factor for the economic aspects (Anbarsooz et al. 2019). Therefore, to obtain wind with higher speeds and more power output, wind turbines are commonly made with long blades and mounted on tall towers, which cause the manufacturing harder and increasing maintenance 


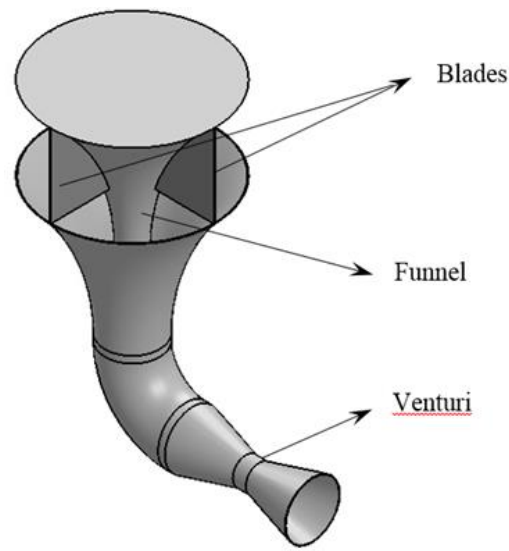

(a)

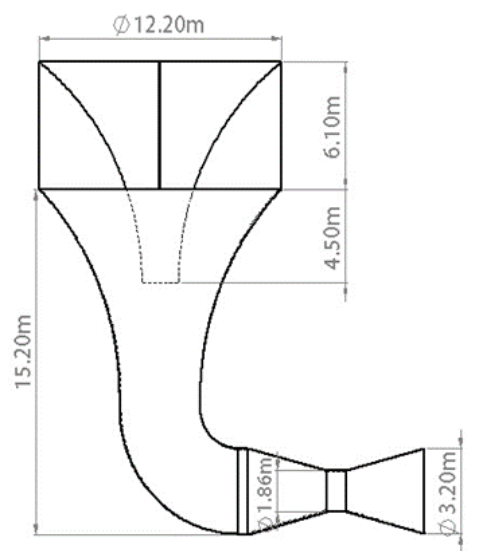

(b)

Fig. 1. (a) Basic design of Invelox, (b) The dimensions of the basic model of Invelox.

costs (Anbarsooz et al. 2019). Adding a duct on a wind turbine is an approach to accelerate the speed of wind so that a wind turbine can start up easily and generate more power. Since wind power is proportional to the wind velocity cubed, a minor increase in wind velocity can dramatically enhance power output (Burton et al. 2001).

Kishore et al. (2013) founded that using a diffuser increased the power output by $40 \%-60 \%$ when compared with a bare one. A flanged diffuser is an improved type. The flange can produce a large flow separation behind the diffuser and capture more mass flow (Abe et al. 2005 ). Ohya et al. (2008) founded that the power output of a HAWT (horizontal axis wind turbine) improved 4-5 times when the flanged diffuser was used. Hu and Cheng (2008) designed a duct with a nozzle outlet. The nozzle outlet can increase the passing flow velocity. They founded that the maximum speed of flow was increased by $60 \%$ inside the duct, but the performance of the wind turbine was also limited by the angle of incident wind (Hu and Cheng 2008). Ahmed (2013) proposed a duct with a group of guide vanes, which could lead airflow downwards. This duct combines some features of diffusers and ducts. The device can capture wind and lead wind to the vertical direction inside the shroud. The maximum flow speed inside the shroud was increased by $20 \%-30 \%$ (Ahmed 2013).

A new concept of wind delivery system was proposed by Allaei et al. (2015), which called INVELOX. As shown in Fig. 1, it is a ducted wind turbine, which not only increases the wind speed, but it brings the wind to the ground level. According to Fig.1-a, the upper section of Invelox is a circular cone with four blades which has the ability to capture air from all directions. Then there is a lower funnel that leads wind toward the Venturi where the speed of air will be increased. The advantages of this design are that the wind turbine is installed in Venturi with higher speed of air near the ground level and there is no need for tall tower and the Yaw mechanism (which horizontal axis wind turbines need) (Anbarsooz et al. 2019).
Allaei et al. (2015) examined the Invelox numerically and experimentally. The numerical simulation and the experimental studies showed that the average speed of air in Venturi was increased by a factor of 1.58 and 1.8, respectively. The improvement of daily energy production of Invelox in comparison to the conventional wind turbine over eight days was about $314 \%$ (Allaei et al.2015).

Instead of using one wind turbine in Venturi of Invelox, Allaei et al. (2015) used multiple wind turbines. Their results showed that adding second and third turbines had an insignificant impact on the performance of the first turbine. They founded, three wind turbines generated $90 \%$ more power than a wind turbine.

Anbarsooz et al. (2017) numerically studied the effects of changing geometrical parameters of the Invelox on its performance by altering the inlet area, upper funnel height and lower diameter of the upper funnel. Their results showed that the inlet area was the most important factor in increasing the speed of air in the Venturi.

Due to escaping large portion of the air from the opposite side of the inlet of Invelox (Fig. 2), Anbarsooz et al. (2019) proposed a novel curtain design to enhance the aerodynamic performance of Invelox. Their numerical simulation showed 25\% increase in average velocity in the Venturi of Invelox. Although the modifications of geometry increased the speed ratio (SR), their results showed that increasing the angle between wind direction and venturi axis had a detrimental effect on the performance of Invelox (Anbarsooz et al. 2019).

The principal goal of this study is to suggest some refinement to the geometry of Invelox to enhance its efficiency in different wind directions. The aims and objectives of the current study are as follows:

Investigation on performance of the original design of Invelox in various wind speeds and different wind directions.

Evaluation the ability of Invelox in capturing more air and increasing speed ratio by changing the number of blades. 


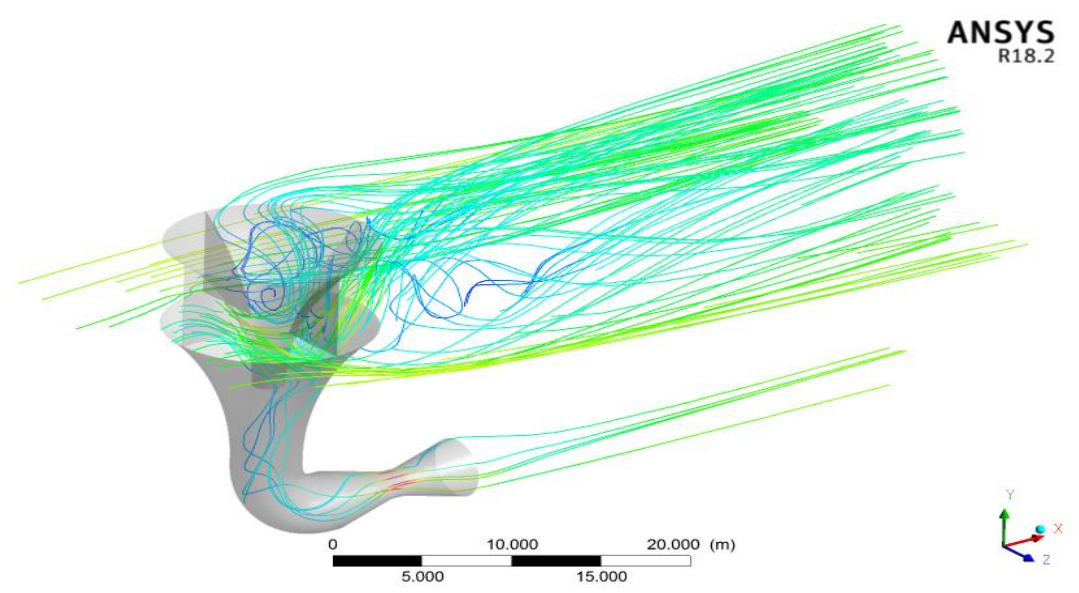

Fig. 2. Showing captured air in veturi of Invelox.

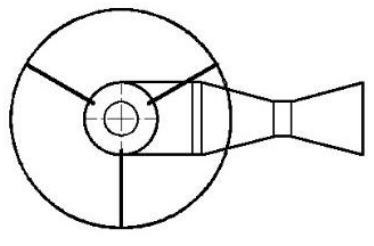

(a)

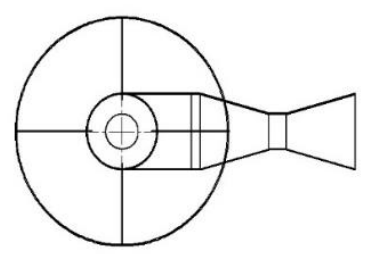

(b)

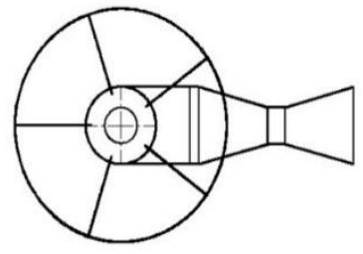

(c)

Fig. 3. Invelox with different blades (a) Three-blade Invelox, (b) four-blade Invelox (basic model), (c) five-blade Invelox.

Studying the effects of increasing the length of the upper funnel.

\section{DESIGNING OF INVELOX}

\subsection{The basic model of Invelox}

The basic model of Invelox was designed by Allaei and Andreopoulos (2014) (Fig. 1.a). Figure 1.b shows the dimensions they used. In this study, in order to compare and validate the results, the same dimensions were used. The original design has been investigated in different wind speeds and directions.

\subsection{Changing the numbers of blades}

As stated before, Anbarsooz et al. (2019) founded that the increase in the angle between the Invelox axis and wind direction causes less performance. In order to understand the effects of blades, Invelox with three, four and five blades have been placed under different wind speeds and directions.

Figure 3 shows the top view of Invelox with different blades (other dimensions are the same as the base model).

\subsection{Increasing the length of the upper funnel}

Although a way to reduce escaping air from the opposite side is to increase the length of the upper funnel, it might well increase the pressure drop
(Anbarsooz et al. 2017). To examine the effects of Increasing funnel length of the four-blade Invelox, $\mathrm{L} / \mathrm{D}$-the dimensionless number was introduced. $\mathrm{L}$ is the length of the upper funnel and D is the upper diameter of the funnel. For the basic design, L/D is equal to 0.9 and two other models were suggested, as shown in Fig. 4.

\section{NUMERICAL SIMULATIN}

\subsection{Governing Equations}

Three dimensional Reynolds-Averaged NavierStokes (RANS) for incompressible flow and steadystate conditions in conservation form can be written as follows (Sotoudeh et al. 2019): Where $s_{i j}=(1 / 2)\left(\partial u_{i} / \partial x_{j}+\partial u_{j} / \partial x_{i}\right)$ is tensor of strain rate.

$\frac{\partial u_{i}}{\partial x_{i}}=0$

$\rho \frac{\partial}{\partial x_{j}}\left(u_{j} u_{i}\right)=-\frac{\partial p}{\partial x_{i}}+\frac{\partial}{\partial x_{j}}\left(2 \mu s_{i j}\right)$

For solving turbulence flow, the field variables ui and $\mathrm{p}$ must be expressed as the sum of mean and fluctuating parts as $u_{i}=U_{i}+u_{i}^{\prime}$ and $p=P+p^{\prime}$. By inserting this definitions into Eqs. (1) and (2), governing equations are (5) and (6) 


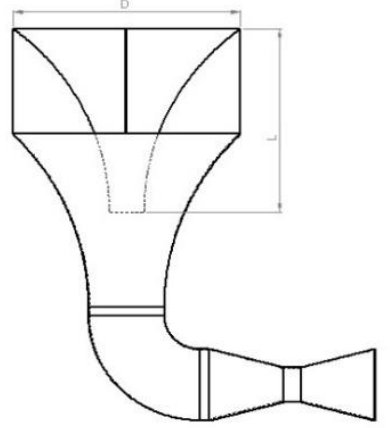

(a)

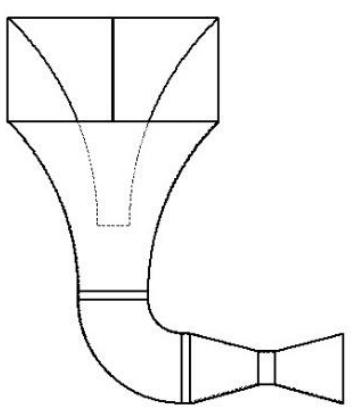

(b)

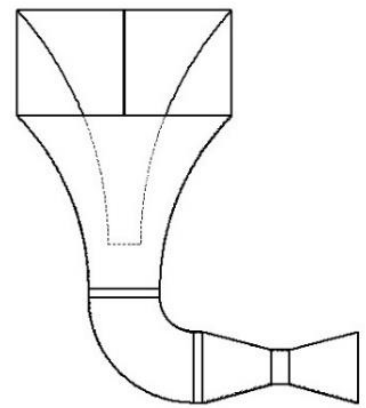

(c)

Fig. 4. Invelox with different lengths of the upper funnel (a) $L / D=0.9$ (basic model), (b) $L / D=1$, (c) $\mathrm{L} / \mathrm{D}=\mathbf{1 . 1}$.

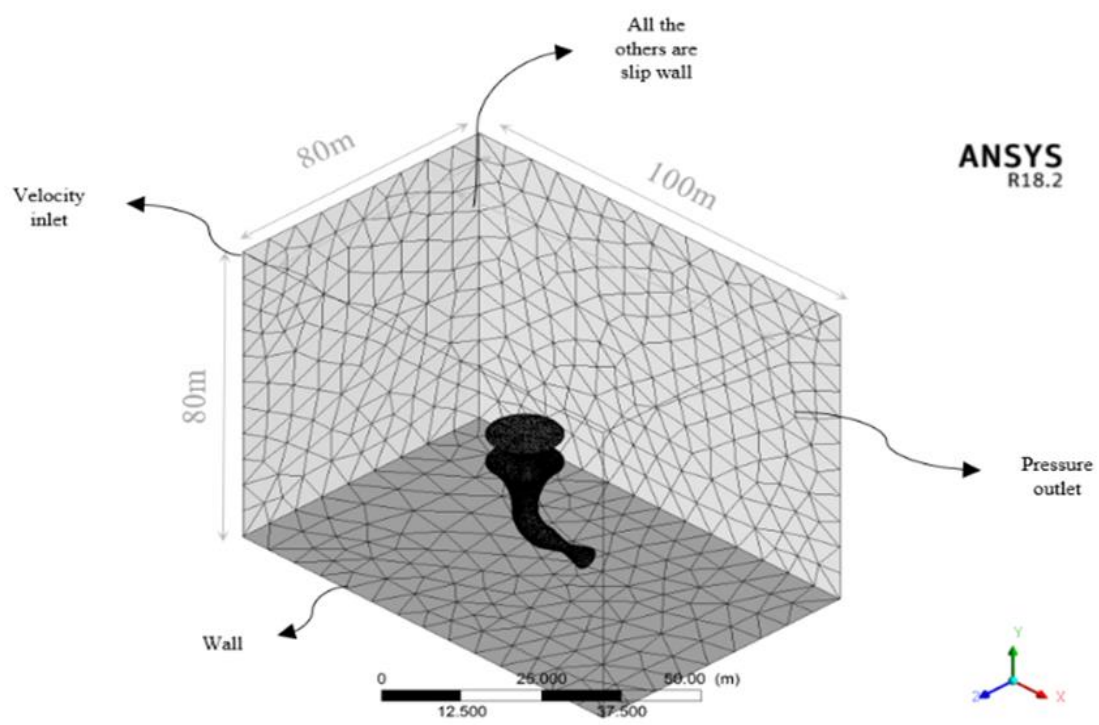

Fig. 5. Computational domain, grid and boundary conditions.

Where $\mathrm{Sij}$ is the mean strain-rate tensor (Eq. (3))

and $\tau_{\mathrm{ij}}$ is the Reynolds stress tensor (Eq. (4)), which needs to be model via a suitable turbulence model.

$$
\begin{aligned}
& S_{i j}=(1 / 2)\left(\partial U_{i} / \partial X_{j}+\partial U_{i} / \partial X_{j}\right) \\
& \tau_{\mathrm{ij}}=-\overline{u_{i}^{\prime} u_{j}^{\prime}} \\
& \frac{\partial U_{i}}{\partial X_{i}}=0 \\
& \rho \frac{\partial}{\partial X_{j}}\left(U_{j} U_{i}\right)=-\frac{\partial P}{\partial X_{i}}+\frac{\partial}{\partial X_{j}}\left(2 \mu S_{i j}-\overline{\rho u_{i}^{\prime} u_{j}^{\prime}}\right)
\end{aligned}
$$

\subsection{Turbulence Model}

For solving the governing equations, Ansys-Fluent 18.2 commercial software was used and four turbulence models consist of $\mathrm{k}-\varepsilon$ standard, $\mathrm{k}-\varepsilon$ RNG, $\mathrm{k}-\varepsilon$ Realizable and k- $\omega$ SST were employed. Kepsilon $(\mathrm{k}-\varepsilon)$ turbulence model is the most common model used in Computational Fluid Dynamics (CFD) to simulate mean flow characteristics for turbulent flow conditions. It is a two-equation model that gives a general description of turbulence by means of two transport equations (PDEs) (Wilcox 1998). The k-E Realizable model contains a new formulation for the turbulent viscosity. The shear stress transport (SST) $\mathrm{k}-\omega$ turbulence model is a two-equation eddyviscosity model for the inner parts of the boundary layer, this model uses a $\mathrm{k}-\omega$ formulation.

Regarding k- $\varepsilon$ standard turbulence model, the k- $\varepsilon$ RNG turbulence model has an extra term in its $\varepsilon$ equation that greatly improves the accuracy for rapidly strained flows and the effect of swirl on turbulence is included, enhancing precision for swirling flows (ANSYS, Inc).

Allaei and Andreopoulos (2014) employed a rectangular cube with dimensions of $50 \mathrm{Dv} \times 40 \mathrm{Dv} \times 40 \mathrm{Dv}$ and $\mathrm{Dv}$ is the diameter of Venturi, which is equal to 1.86 meters. In order to compare results, the similar domain is used in this project, as shown in Fig. 5.

Boundary conditions are the same as Allaei and Andreopoulos (2014), include: velocity inlet is $6.7 \mathrm{~m} / \mathrm{s}$, pressure outlet at exit plane was used which 
A. Farokhzade and M. J. Maghrebi/ JAFM, Vol. 14, No. 5, pp. 1511-1520, 2021.

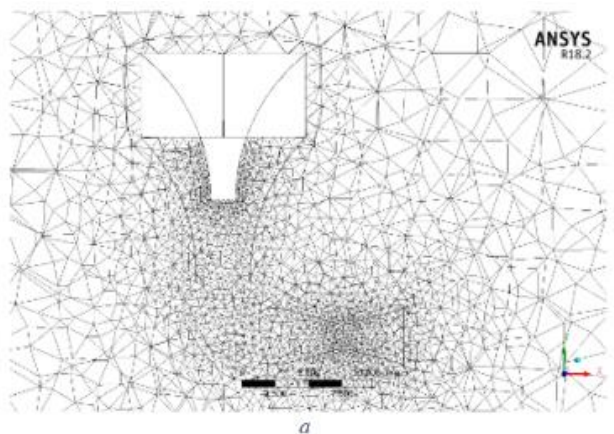

(a)

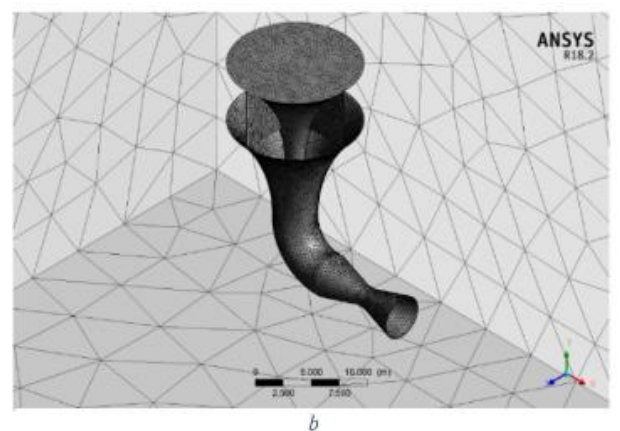

(b)

Fig. 6. Invelox grid distribution (a) 2-D view, (b) 3-D view.
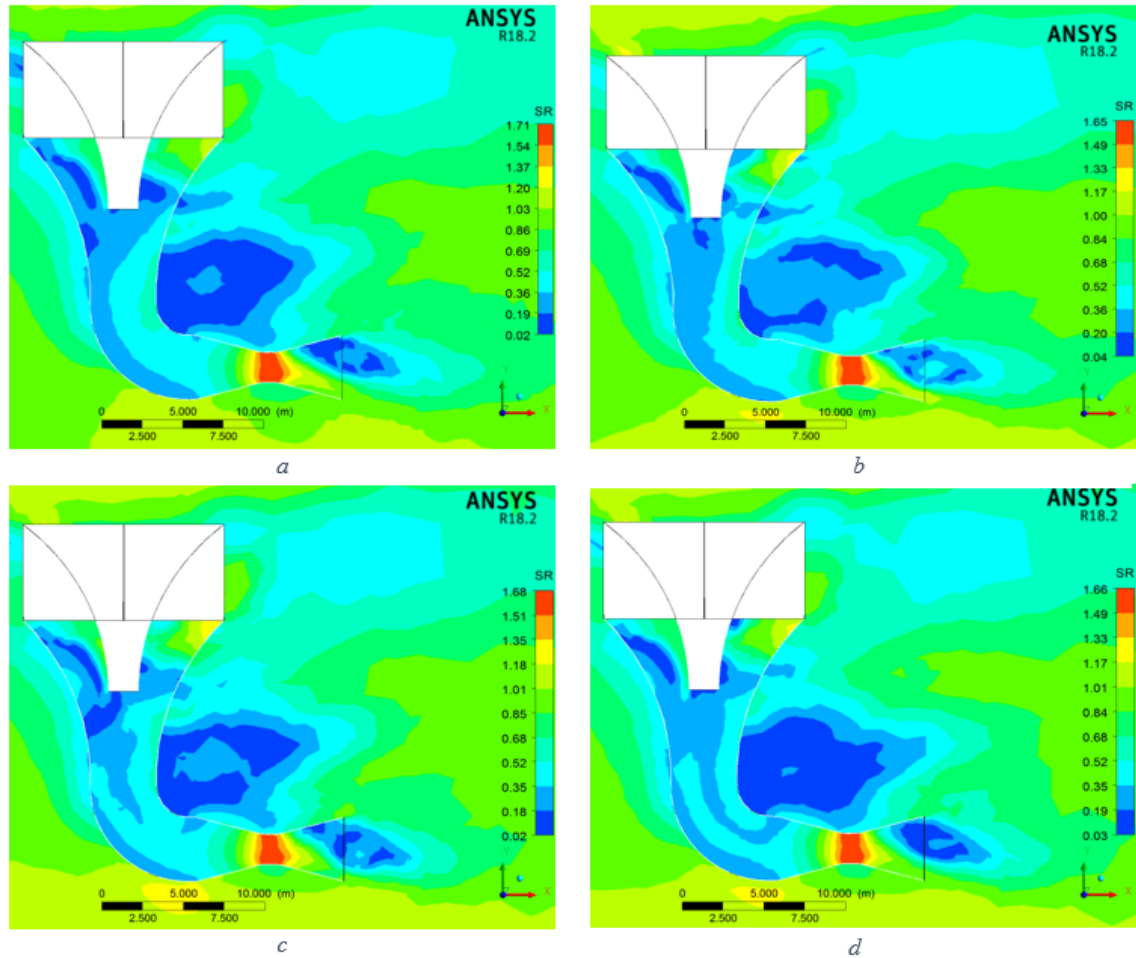

Fig. 7. Dimensionless contours of velocity on a median cross section of Invelox, using different turbulence models. Inlet velocity for all cases is $6.7 \mathrm{~m} / \mathrm{s}$ (a) Standard $k-\varepsilon$, (b) RNG k-E, (c) SST k- $\omega$, (d) Realizable k- $\varepsilon$.

equal to atmospheric pressure, the ground was set wall with no-slip condition and all other surfaces were considered slip walls.

Unstructured tetrahedral cells are employed for discretising the domain and for more accurate results, smaller cells are used near the Invelox, as shown in Fig. 5 and Fig. 6. For mesh independency, $1,1.25$, and 1.5 million cells were utilized.

\section{Results}

The dimensionless coefficient was defined to be used for the rest of the results:

Speed Ratio average $($ SRavg $)=$
Average velocity in venturi / inlet velocity )

Speed Ratio maximum $($ SRmax $)=$

Maximum velocity in venturi/inlet velocity

\subsection{Numerical verification and validation}

As stated before, four turbulence models were used to solve the problem. Figure 7 shows the dimensionless contour of velocity by using four turbulence models. The inlet velocity is set $6.7 \mathrm{~m} / \mathrm{s}$ aligned with the $\mathrm{x}$-axis for the four cases. According to Fig. 7, Maximum speed ratio for k- $\varepsilon$ standard, k- $\varepsilon$ RNG, k- $\varepsilon$ Realizable and k- $\omega$ SST turbulence model is equal to $1.71,1.65,1.66$ and 1.68 , respectively. 
A. Farokhzade and M. J. Maghrebi/ JAFM, Vol. 14, No. 5, pp. 1511-1520, 2021.

Table 1 Comparison between results of this study and Anbarsooz et al. (2019).

\begin{tabular}{|c|c|c|c|}
\hline Turbulence Model & SRavg & $\begin{array}{c}\text { SRavg Anbarsooz } \text { et al. } \\
(2019)\end{array}$ & Relative error (\%) \\
\hline k- $\varepsilon$ RNG & 1.61 & 1.57 & 2.55 \\
\hline k- $\varepsilon$ Realizable & 1.56 & 1.48 & 5.41 \\
\hline k- $\varepsilon$ Standard & 1.61 & 1.57 & 2.55 \\
\hline k- $\omega$ SST & 1.56 & 1.52 & 2.63 \\
\hline
\end{tabular}

Table 2 Comparison between results of this study and experimental and numerical results of Allaei and Andreopoulos (2014).

\begin{tabular}{|c|c|c|c|}
\hline \multirow{2}{*}{ Turbulence Model } & \multirow{2}{*}{ SRavg } & \multicolumn{2}{|c|}{ Relative error (\%) } \\
\cline { 3 - 4 } & & Experimental (SRavg=1.8) & Numerical (SRavg=1.58) \\
\hline k- $\varepsilon$ RNG & 1.61 & 10.56 & 1.90 \\
\hline k- $\varepsilon$ Realizable & 1.56 & 13.33 & 1.27 \\
\hline k- $\varepsilon$ Standard & 1.61 & 10.56 & 1.90 \\
\hline k- $\omega$ SST & 1.56 & 13.33 & 1.27 \\
\hline
\end{tabular}

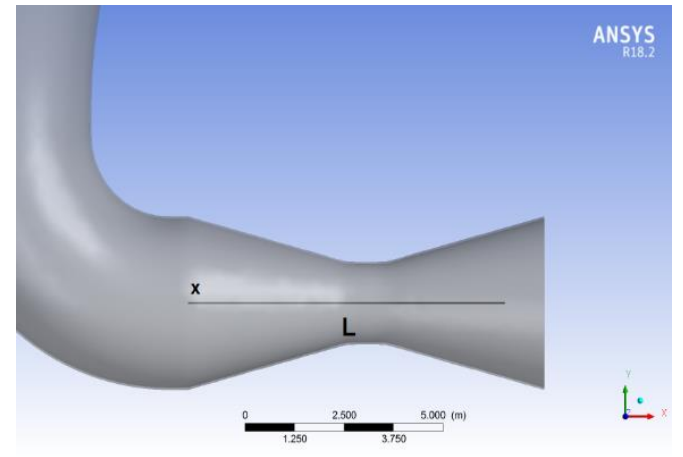

Fig. 8. Schematic of line $L$ at the center of converging-diverging nozzle.

Table 1 shows the comparison between the average velocity of this project and the numerical results of Anbarsooz et al. (2019). All turbulence models have predicted average speed ratio with less than $6 \%$ error.

To validate the results, the average speed ratio is compared to the numerical and experimental results of Allaei and Andreopoulos (2014), which is equal to 1.58 and 1.8 , respectively. Table 2 shows less than $2 \%$ error in numerical and less than $14 \%$ error in experimental results. As reported by Table 1 and Table 2, the results of this project are nearly similar to those of Anbarsooz et al. (2019) and those of Allaei and Andreopoulos (2014). The k- $\varepsilon$ RNG turbulence model has an extra term in its $\varepsilon$ equation and the effects of swirl on turbulence are predicted (regarding the flow inside the Invelox turns and swirls) with more precision in comparison to other turbulence models.

According to Table 1 and Table 2, for the rest of the numerical simulations of this project, the k- $\varepsilon$ RNG turbulence model and 1.25 million cells for discretising domain were utilized.

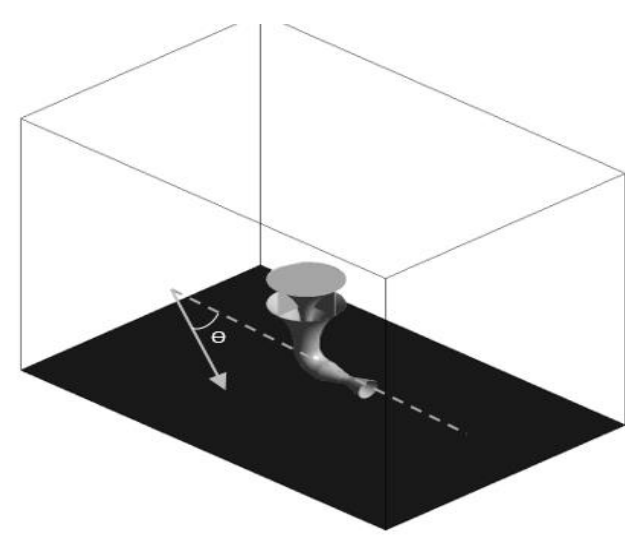

Fig. 9. Schematic of the angle between wind direction and venturi axis $(\Theta)$.

\subsection{Basic design}

Five different velocity inlet have been used to determine Invelox performance at various wind speeds. For better comparison, the speed ratio has been measured on a line with length of $L$ at the centre of the converging-diverging nozzle (Fig. 8). Subsequently, the direction of the wind has been changed while the speed of wind was kept constant at $6.7 \mathrm{~m} / \mathrm{s}$. According to Fig. 9, the angle between wind direction and Venturi axis is $\Theta$ and has been altered from zero to 60 degrees.

Figure 10 shows a comparison between speed ratios in different wind speeds on the line of L. However the speed ratio is almost independent of the wind speed, at higher wind velocities, the vorticity generation at walls are stronger and therefore a more accurate approximation for turbulence viscosity is required (Anbarsooz et al. 2019). At $\mathrm{x} / \mathrm{L}=0$, the pressure of air increases so by utilizing Bernoulli's equation $\left(P / \gamma+U^{2} / 2 g+Z=\right.$ constant $)$, the velocity of air in Invelox decreases, Continuity Equation ( $Q=U A$ ) shows by decreasing the 


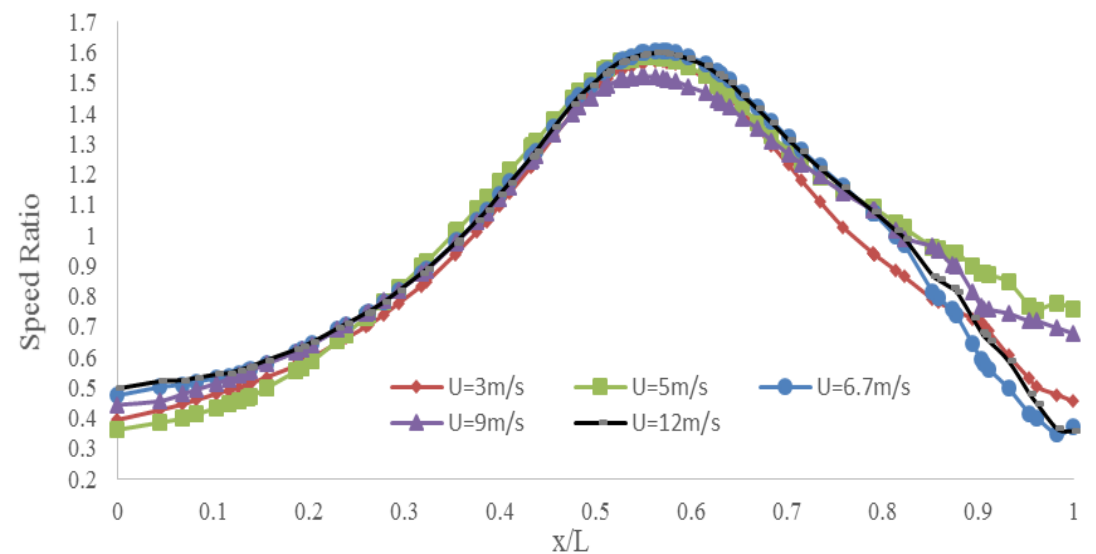

Fig. 10. Speed ratio on line of $L$ in different wind speeds for the basic model of Invelox.

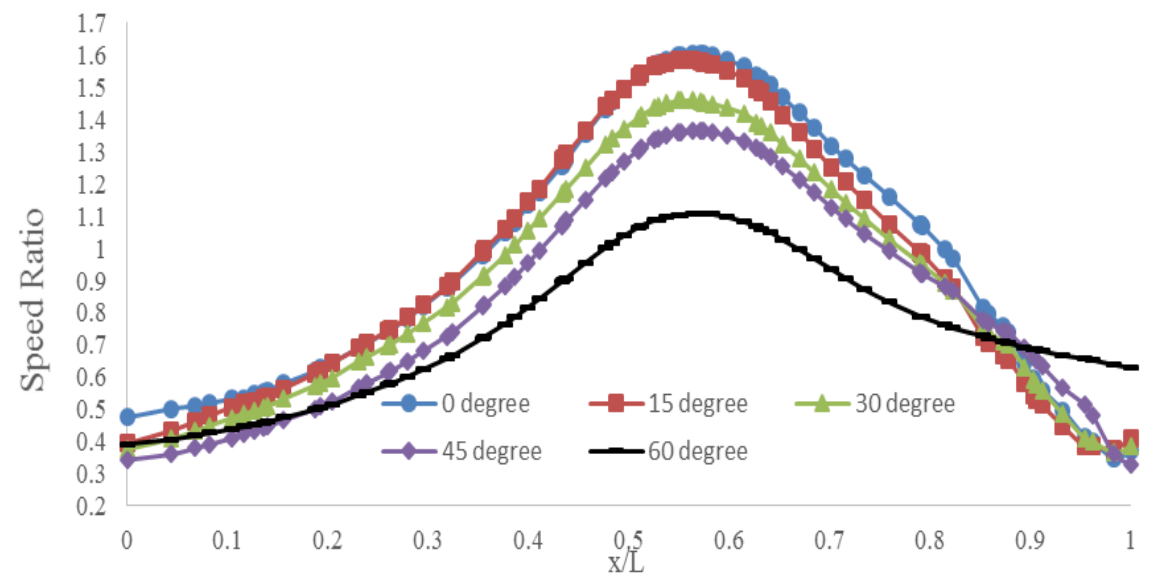

Fig. 11. Speed ratio on line of $L$ in different wind directions and the same inlet velocity $(6.7 \mathrm{~m} / \mathrm{s})$ for the basic model of Invelox.

area at $\mathrm{x} / \mathrm{L}=0.5$ the speed of air in venturi increases (Batchelor 2000).

Due to gradient of pressure between inside of Invelox and surrounding as well as difference of mesh size (according to Fig. 5 and Fig. 6), the values of speed ratio spread at $\mathrm{x} / \mathrm{L}=1$ (at diverging region of nozzle).

According to Fig. 11, speed ratio and $\Theta$ angle are interdependent, which increases the angle cause reduction in speed ratio. Because air velocity has components that make reverse flow at windward of Invelox and then block the air to enter it.

\subsection{Invelox with different blades}

As stated before, Invelox has the potential to work at different wind speeds but its efficiency decreases when the wind is not coaxial with the Venturi axis. Therefore, Invelox with 3 and 5 blades have been proposed and compared to the four-blade version.

To understand the characteristic of flow in different inlet directions, Fig. 12, Fig. 13 and Fig. 14 have been drawn, which show the velocity vector from the top plain for all three Inveloxes (the angle of the inlet direction is zero and 45 degrees). According to
Fig.12, Fig.13 and Fig.14, when the inlet angle is zero, no reverse flow observed in the windward of Invelox. However, there is a reverse flow that does not allow the mass to be captured for $\Theta=45$ degrees. Therefore, the performance of Inveloxes decreases.

The five-blade Invelox is more capable of capturing air because the portion of reverse flow is fewer than the others. In order to have a better comparison to four-blade Invelox Fig. 15 and Fig. 16 have been drawn.

The speed ratio does not change for each Invelox in different wind speeds (Fig. 15). The four-blade Invelox shows better performance as compared to others for aligned inlet velocities. Because the speed of wind at inlet of Invelox is almost zero (due to placement of blades) so pressure increases at inlet according to Bernoulli's equation. The difference of pressure between inlet and venturi pulls more air into Invelox and increases speed of wind in venturi.

According to Fig. 16, although the efficiency of all three Inveloxes decreases by increasing the angle of $\Theta$, five- blade Invelox has the capability to increase the speed ratio about 2 to 6 percent more when compared with the basic design, which leads to more power output. 
A. Farokhzade and M. J. Maghrebi/ JAFM, Vol. 14, No. 5, pp. 1511-1520, 2021.
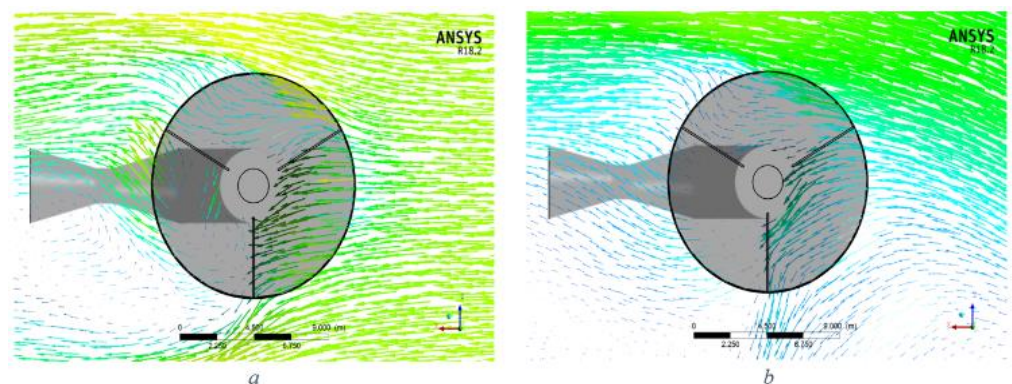

Fig. 12. Vector of velocity from the top view in Inveloxes (a) Three- blade Invelox. $\theta=0$ degree, (b) Three- blade Invelox. $\Theta=45$ degrees.
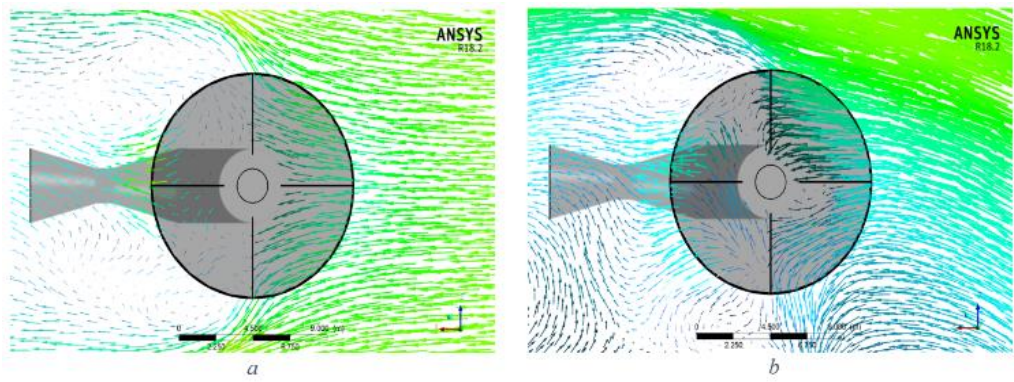

Fig. 13. Vector of velocity from the top view in Inveloxes (a) four- blade Invelox. $\theta=0$ degree, (b) four- blade Invelox. $\theta=45$ degrees.
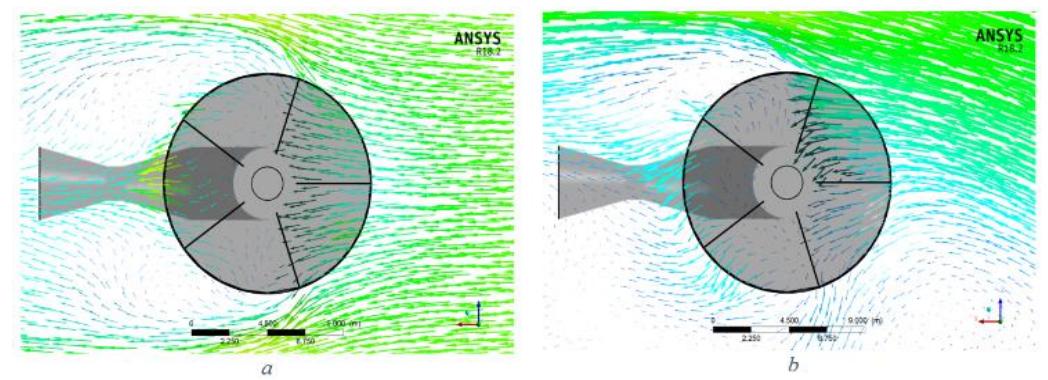

Fig. 14. Vector of velocity from the top view in Inveloxes (a) five- blade Invelox. $\theta=0$ degree, (b) five- blade Invelox. $\Theta=45$ degrees.

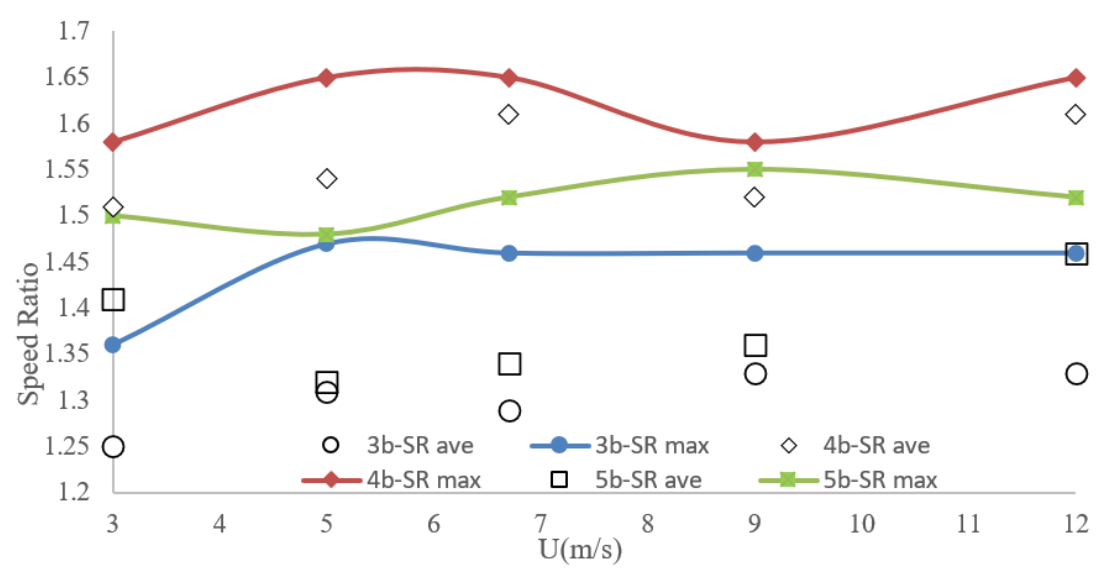

Fig. 15. Comparison between basic model of Invelox and proposed Inveloxes in different wind speeds ( $3 \mathrm{~b}, 4 \mathrm{~b}$ and $5 \mathrm{~b}$ are three-blade, four-blade and five-blade Invelox, respectively). 


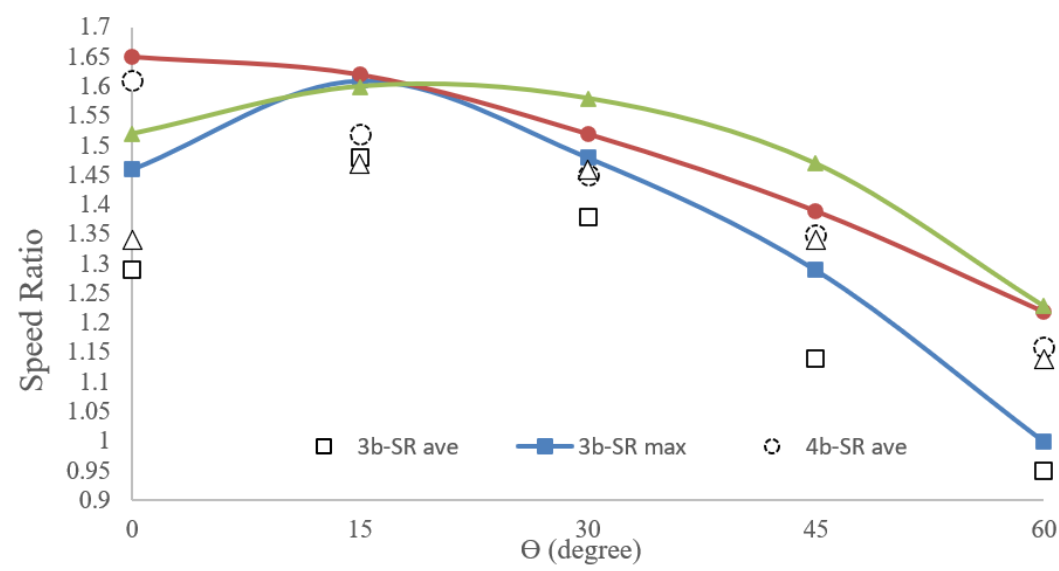

Fig. 16. Comparison between basic model of Invelox and proposed Inveloxes in different wind directions ( $3 \mathrm{~b}, 4 \mathrm{~b}$ and $5 \mathrm{~b}$ are three-blade, four-blade and five-blade Invelox, respectively).

Table 3 Comparison between inveloxes with different lengths of the upper funnel.

\begin{tabular}{|c|c|c|c|c|}
\hline L/D & SRavg & $\begin{array}{c}\text { Improvement } \\
(\%)\end{array}$ & SRmax & $\begin{array}{c}\text { Improvement } \\
(\%)\end{array}$ \\
\hline 0.9 & 1.61 & - & 1.65 & - \\
\hline 1 & 1.68 & 4.35 & 1.71 & 3.64 \\
\hline 1.1 & 1.65 & 2.48 & 1.69 & 2.42 \\
\hline
\end{tabular}

\subsection{Increasing the length of the upper funnel}

Table 3 shows the results of increasing the length of the upper funnel and improvement percent. As stated before, increasing the length of funnel help Invelox capture more air. On the other hand, it increases the pressure drop.

\section{CONCLUSION}

Previous studies about Invelox have shown that it has the potential to increase the wind speed, which leads to increasing the power output. But, increasing the angle between wind and Venturi axis decreases the performance of Invelox.

The wind power is proportional to the wind velocity cubed $\left(P_{T} \propto U^{3}\right)$, increasing wind speed

can dramatically enhance power output.

In this study, it has been tried to increase the aerodynamic performance by some geometrical changes, including:

Changing the number of blades, which increases the speed ratio (SR) about 2 to 6 percent when the wind direction is not coaxial with the Venturi axis. This increases the power output about 7 to 20 percent.

Increasing the length of the upper funnel, which increases the speed ratio about 2 to 4 percent. That means the power output increases about 7 to 12.5 percent.
Furthermore, it was found that the effects of changing the wind speed are negligible for SR in suggested Inveloxes. However, the four-blade version performs better in increasing wind speed.

\section{ACKNOWLEDGEMENTS}

We hereby acknowledge that parts of this computation was performed on the HPC (High Performance Computing) center of Ferdowsi University Of Mashhad.

\section{REFERENCES}

Abe, K., M. Nishida, A. Sakurai, Y. Ohya (2005) Experimental and numerical investigations of flow fields behind a small wind turbine with a flanged diffuser. Journal of Wind Engineering and Industrial Aerodynamics 93, 951-970.

Ahmed, N. A. (2013). A novel small scale efficient wind turbine for power generation. Renewable Energy 57, 79-85.

Allaei, D., D. Tarnowski and Y. Andreopoulos (2015). INVELOX with multiple wind turbine generator systems. Energy 93 (Part 1),1030-40.

Allaei, D. and Y. Andreopoulos (2014). INVELOX: Description of a new concept in wind power and its performance evaluation. Energy 69, 336344.

Anbarsooz, M., M. S. Hesam and B. Moetakef-Imani 
A. Farokhzade and M. J. Maghrebi/ JAFM, Vol. 14, No. 5, pp. 1511-1520, 2021.

(2017). Numerical study on the geometrical parameters affecting the aerodynamic performance of Invelox. IET Renew Power Gener 11(6), 791-8.

Anbarsooz, M., M. Amiri and I. Rashidi(2019). A novel curtain design to enhance the aerodynamic performance of Invelox: a steadyRANS numerical simulation. Energy 168, 207221

ANSYS, Inc. ANSYS manual, Release 18.2.

Batchelor, G. K. (2000). An Introduction to Fluid Dynamics. Cambridge: Cambridge University Press.

Bonass, M. and M. Rudd (2010). Renewables: A Practical Handbook. London: Globe Law and Business, pp. 51.

Burton, T., D. Sharpe, N. Jenkins and E. Bossanyi(2001). Wind energy handbook, Chichester, UK: John Wiley \& Sons, Ltd., 2001.

Eriksson, S., H. Bernhoff and M. Leijon (2008). Evaluation of different turbine concepts for wind power. Renewable and Sustainable Energy Reviews 12, 1419-1434.

Grant, A., C. Johnstone and N. Kelly (2008). Urban wind energy conversion: the potential of ducted turbines. Renew. Energy 33(6), 1157-1163
Hu, S. Y. and J. H. Cheng (2008). Innovatory designs for ducted wind turbines. Renewable Energy 33, 1491-1498.

Kishore, R. A., T. Coudron and S. Priya (2013). Small-scale wind energy portable turbine (SWEPT). Journal of Wind Engineering and Industrial Aerodynamics 116, 21-31.

Kyozuka, Y. (2008). An experimental study on the Darrieus-Savonius turbine for the tidal current power generation. Journal of Fluid Science and Technology 3, 439-449.

Ohya, Y., T. Karasudani, A. Sakurai, K. Abe (2008). Development of a shrouded wind turbine with a flanged diffuser. Journal of Wind Engineering and Industrial Aerodynamics 96, 524-539.

Sotoudeh, F., R. Kamali and S. M. Mousavi (2019). Field tests and numerical modeling of INVELOX wind turbine application in low wind speed region. Energy 181, 745-759

Walker, S. L. (2011). Building mounted wind turbines and their suitability for the urban scaled review of methods of estimating urban wind resource. Energy Build 43(8), 1852-62.

Wilcox, D. C. (1998). Turbulence Modeling for $C F D$. Second edition. Anaheim: DCW Industries, 1998. pp. 174. 